\title{
SEGMENTING TOWNSHIP RESIDENTS BY THEIR ATTITUDES, BEHAVIOURS, AND OPINIONS TOWARDS RESPONSIBLE TOURISM PRACTICES
}

\author{
Jacqueline J. MANGWANE* \\ Centre for Sustainable Tourism, Tshwane University of Technology, \\ Department of Tourism Management, South Africa, email: mangwanej@tut.ac.za \\ Ndivhuwo N. TSHIPALA \\ Centre for Sustainable Tourism, Tshwane University of Technology, \\ Department of Tourism Management, South Africa, email: tshipalann@tut.ac.za \\ Athenkosi NTANJANA \\ Centre for Sustainable Tourism, Tshwane University of Technology \\ Department of Tourism Management, South Africa, email: ntanjanaa@tut.ac.za \\ Beverly M. MAKOPO \\ Centre for Sustainable Tourism, Tshwane University of Technology \\ Department of Tourism Management, South Africa, email: makopobm@tut.ac.za
}

\begin{abstract}
Citation: Mangwane, J., Tshipala N.N., Ntanjana, A., \& Makopo B.M. (2019). SEGMENTING TOWNSHIP RESIDENTS BY THEIR ATTITUDES, BEHAVIOURS, AND OPINIONS TOWARDS RESPONSIBLE TOURISM PRACTICES. GeoJournal of Tourism and Geosites, 27(4), 13571366. https://doi.org/10.30892/gtg.27420-439
\end{abstract}

\begin{abstract}
This article departs from the premise that the immense social and economic value that the tourism industry has in South African townships calls for a need to encourage responsible tourism behaviour among local residents. Responsible tourism behaviour is behaviour that seeks to minimise the negative impacts of tourism and maximise the positive impacts on the socio-cultural, economic, and ecological environment. Minimising the negative tourism impacts is important since these may have implications for the future growth and development of the tourism sector. The aim of this study was to segment residents in a South African township by examining their attitudes and behaviour towards responsible tourism practices. Three hundred respondents completed a selfadministered questionnaire. A statistical analysis using paired comparison revealed that certain behaviours of residents differ when they are at home and when they are travelling. The results revealed that residents are aware of responsible tourism practices such as waste reduction and the mindful use of water and electricity. However, it is concerning to note that when travelling, residents' use of water and electricity differs significantly from when they are at home. This could be because when travelling, they are not liable for the financial implications regarding the amount of water and electricity used. This study could assist communities and
\end{abstract}

\footnotetext{
* Corresponding author
} 
Jacqueline MANGWANE, Ndivhuwo N. TSHIPALA, Athenkosi NTANJANA, Berverly M. MAKOPO

different tourism organisations and associations to develop awareness campaigns that encourage people to be more environmentally responsible when travelling.

Key words: responsible tourism, township, segmentation, behaviour, South Africa

\section{INTRODUCTION}

According to the World Travel \& Tourism Council (WTTC, 2019), the tourism sector creates jobs, drives exports, and generates prosperity worldwide. The sector consists of a wide variety of industries that aim to serve and support domestic, international, business, and leisure visitors. Small, medium, and large companies in industries ranging from accommodation and transportation to food and beverage, retail and culture, and sports and recreation all strive to create products and services that bring people together, support communities, and celebrate the natural and cultural wonders that the world can offer. In the annual analysis of 2018, the WTTC revealed that the global economic and employment impact of the tourism sector in 185 countries and 25 regions accounted for $10.4 \%$ of global GDP and 319 million jobs, or $10 \%$ of total employment (WTTC, 2019). In line with the WTTC (2019), the National Department of Tourism (NDT, 2017) in South Africa reported that the immense social and economic value of the tourism sector continues to improve the lives of millions of people in the country.

The sector directly and indirectly created approximately 1.5 million jobs in 2017, 9.5\% of total employment. In addition, the NDT (2017) anticipates that the sector will create 2.1 million jobs by 2028. In order to guarantee this growth and ensure that it leads to real economic and social transformation for South Africans, it is critical that the sector vigorously promotes the values that form the foundation of sound, responsible, and sustainable tourism and avoids unguided forms of tourism that could be inflicted on the environment, society, and the economy (Cape Town Declaration on Responsible Tourism, 2002). The United Nations Educational, Scientific and Cultural Organization (UNESCO, 2009) Regional Bureau for Science and Culture in Europe (BRESCE) points out that all forms of tourism have an environmental, social, and economic impact on the destination involved. In agreement, Hanafiahet al. (2016) posit that the tourism industry experiences various sustainability challenges such as resource manipulation and economic instability.

Determining how to minimise the negative tourism impacts is important since such impacts may have implications for the future growth and development of the tourism sector. Dolnicar et al. (2019) recognise that responsible tourism behaviour can minimise environmental problems and can be considered a solution to the negative environmental impacts created by those who use tourism products and services. Bob (2016) ass erts that information dissemination through practices such as awareness campaigns may encourage people to be more environmentally responsible when travelling. Ridderstaat et al. (2014) suggest that to maintain sustainable tourism, local communities must engage in responsible tourism initiatives and must practise responsible tourism ethics during the management and operation of their tourism businesses.

Similarly, Eraqi (2014) emphasises that a community that practises responsible tourism develops a dynamic tourism industry, which is subsequently environmentally, socially, culturally, and economically sustainable. According to Hanafiah et al. (2016), tourism policymakers must promote and make available the benefits of renewal and resilience to the residents and the area. Researchers such as Dolnicar et al. (2019), Bob (2016), Barr et al. (2010) emphasise the importance of undertaking research in this area 
because responsible tourism behaviour of the local residents is crucial in enhancing tourism sustainability. Thus, this study investigated the demographic and tourism behavioural descriptors of township residents in Soshanguve.

\section{LITERATURE REVIEW}

\section{Responsible township tourism}

According to Booyens (2010), since the dawn of democracy in 1994, township tourism in South Africa has been growing and has been considered a stimulant for local economic development. The cultural and heritage aspects of tourism products are said to be growing in popularity at a faster rate than other forms of tourism (Chili, 2015). South Africa is increasingly receiving significant numbers of visitors who are interested in township tourism (Booyens, 2010). Township tourism typically involves visitors travelling to poverty-stricken areas to see how the people live (Nemasetoni \& Rogerson, 2017). Since township tourism tends to attract a relatively small share of the tourism market, this form of tourism is recommended for destinations that either have no resources or wish to develop into a mass tourism destination (Rogerson, 2005).

Booyens (2010) cited the following guidelines for responsible township tourism:

- Locals should have the opportunity to take part in decision-making, be employed, be trained and empowered, and become owners of tourism products.

- Local goods and services should be procured.

- Local entrepreneurship and small business development should be promoted.

- Local cultures should be respected and protected.

- Natural, cultural, and heritage resources should be preserved.

- Developments should be sensitive to the environment.

Despite the increase in the popularity of township tourism, there is a dearth of published research on responsible township tourism in South Africa (George \& Booysens, 2014). Internationally, Cheng et al. (2019) reveal that a considerable number of studies identify environmentally responsible behaviour of residents as a significant indicator of sustainable tourism development. Research indicates that if individuals or groups are able to form attitudes and perceptions concerning sustainable development, they are likely to grasp and take preventative measures and offer solutions for environmental issues and in turn, show appreciation and empathy towards environmental and community issues with a sense of attachment and stewardship (Rosli \& Ahmad, 2018). Environmentally responsible behaviour includes personal habits and collective actions (Cheng et al., 2019).

Responsible tourism behaviour can be defined as the behaviour that consciously seeks to minimise the negative impacts of tourism and maximise the positive impacts on the socio-cultural, economic, and ecological environment (Tichaawa \& Samhere, 2015; Poudel \& Nyaupane, 2017). According to Varela-Candamio et al. (2018), through learning new environmental attitudes and responsibilities, behavioural intentions can be altered. Many studies also see environmentally responsible behaviour as a consequence of environmental attitudes (Chiu et al., 2014; Liao \& Satchabut, 2017).

Furthermore, a considerable number of current studies demonstrate both negative and positive tourism behavioural practices by local residents. For example, residents' influence on tourism development includes the in situ stage of image formation, which determines tourists' on-site experience, satisfaction with the destination, and word-ofmouth recommendations (Stylidis, 2018). This is because local residents serve as a primary source of information for visitors due to their familiarity with the destination (Brida et al., 2010). This indicates that residents play a crucial role in shaping the image of tourist destinations. According to Stylidis (2018), studies reveal that there is a positive 
relationship between the role of residents and their support for tourism development. In contrast, empirical research suggests that local residents who harbour a negative image often lack a sense of attachment and stewardship regarding community matters. Maruyama \& Woosnam (2015) purport that understanding how residents behave towards tourism is imperative for the sustainable development of a tourist destination. It is, therefore, relevant to understand residents' demographic and tourism behavioural descriptors in shaping the image of a township as a tourist destination.

\section{Demographic segmentation}

Demographic descriptors are used to determine the observable demographics that differentiate one segment from another (Goyat, 2011). Variables such as age, gender, family size, family life cycle, income, occupation, education, generation, ethnicity, nationality, religion, and social class form the basis of demographic segmentation (Goyat, 2011; Veisten et al., 2015).Understanding the demographic characteristics of travellers helps to create a more thorough tourist profile (Tichaawa \& Harilal, 2016; Alén et al., 2017). The study of tourist demographic characteristics is also useful in the formulation of marketing strategies (Duman \& Tanrisevdi, 2011) and provides useful information for policy-makers and tourism managers for strategy formulation, product development, and service delivery (Brida et al., 2010).

\section{Behavioural segmentation}

Tourism studies use segmentation widely to categorise diversified groups and thus identify niche markets for tourism products and services (Park \& Yoon, 2009; Rid et al., 2014). In addition, the purpose of segmentation is to adapt marketing practices (i.e. development, offerings of wanted products, and promotion) to the needs of specific target groups (Park \& Yoon, 2009). According to Kotler et al. (1999), marketers generally perceive behavioural segmentation to be the best method for initiating market segmentation. Numerous scholars are of the opinion that behavioural segmentation is a more effective extrapolative option for tourism behaviour than socio-demographic segmentation (Dryglas \& Salamaga, 2017; Tkaczynski et al., 2009).

According to Mahdzar \& Gani (2018), behavioural segmentation is also referred to as psychographic segmentation, and psychographic variables include activities, interest, opinion, attitudes, and values. Mahdzar \& Gani (2018) further posit that this type of segmentation divides the market into groups according to visitors' lifestyles. This simply means that numerous possible influences on a resident's behaviour are considered, including attitudes and activities. In their study on the psychographic and behavioural descriptors of ecotourists within the Capricorn District Municipality, Silent et al. (2018) found behavioural descriptors to be an effective means of segmenting ecotourists in that region. Consequently, it is important to explore behavioural patterns of township residents regarding responsible tourism practices to inform development policies more effectively and to provide a better understanding of township tourists.

As cited by Nkemngu (2012), according to the 2011 annual report of the Gauteng Tourism Authority, the history of human occupation in the township referred to today as Soshanguve dates back 200000 years. The township as it currently appears came into being in 1972. The name Soshanguve comes from the indigenous groups that settled there after they were forcefully relocated by the apartheid government in 1972. The indigenous groups comprise Sotho, Shangaan, Nguni and Venda (Nkemngu, 2012). However, more recently, a more broadly encompassing explanation has been suggested: Sotho, Shangaan, Afrikaans, Nguni, Venda, and English. As quoted by Anyumba (2017, p.3), "[a]ll townships in South Africa are characterized by either 'liberation struggle' credentials, a rich architectural heritage, or black enterprise that was 'throttled' by the system of 
apartheid and spatial locations far removed from city centers". Soshanguve lies about $45 \mathrm{~km}$ north of Pretoria, Gauteng, South Africa (Figure 1).

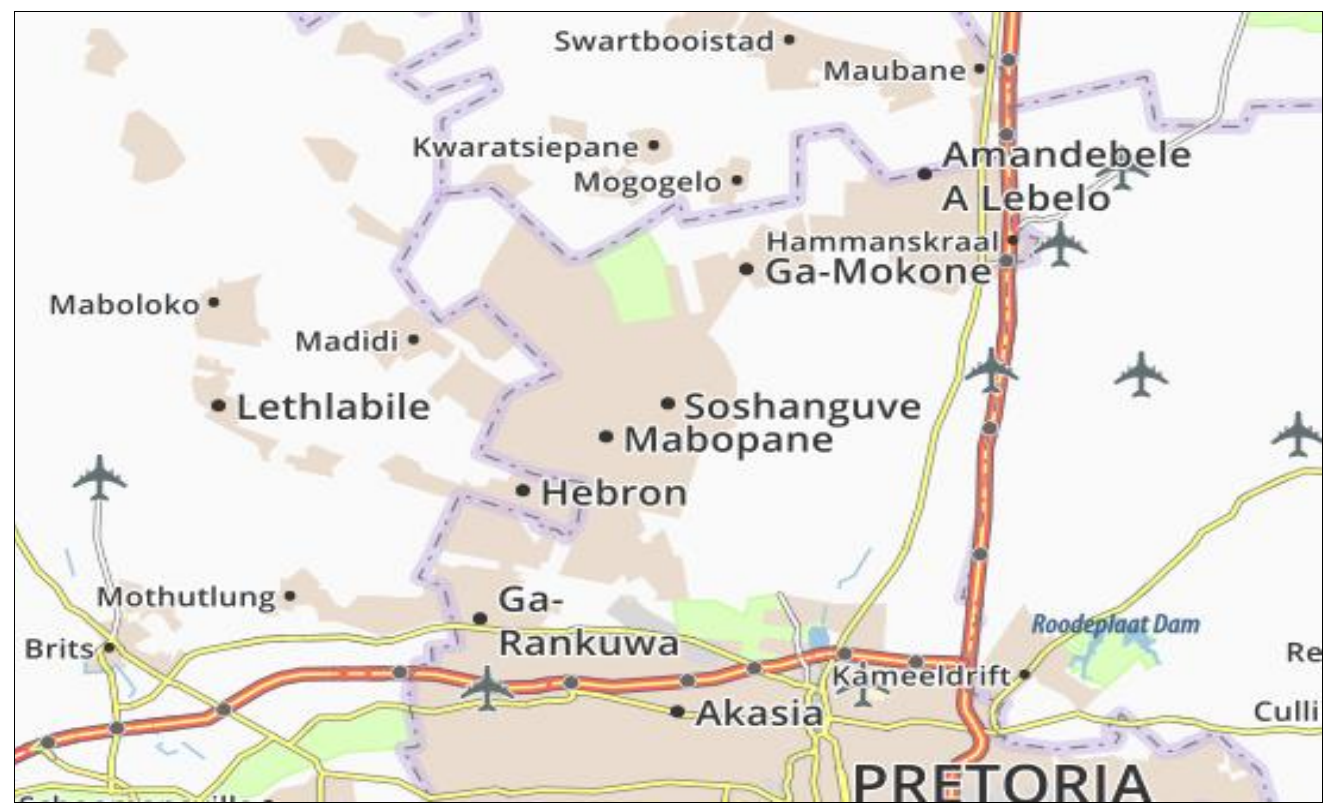

Figure 1. Map of Soshanguve (Source: Viamichelin.com)

The township offers a special natural attraction within its confines, the Tswaing crater. The historical and natural landscape of Soshanguve creates a unique and competitive advantage over other townships. Infrastructural developments including road networks, electricity supply to households, tap water provision, and the opening of shopping centres such as the Soshanguve Crossing Mall makes Soshanguve a tourism force that provides opportunities to fill gaps and add to the body of knowledge, thus prompting the study. In addition, global literature on slum tourism mostly focuses on the debate about whether township tourism is voyeuristic or not (Pickard, 2007; Gross, 2010).

\section{MATERIALS AND METHODS}

The research design of this study was exploratory because prior to the study, very little or no information was available on the tourism phenomena being investigated (Jennings, 2010). The research design was a survey and thus, the epistemology of this study is known as positivism, which means that the researchers used quantitative sciences to create new knowledge and analyse data (Robert, 2010). Bryman (2012) argues that a positivist stance is objective and only considers facts, not respondents' subjective feelings.

Vanderstoep \& Johnston (2009) define a population as the study of a universe of people to which the study can be generalised. The population for this study comprised residents who visited Soshanguve Township. According to Bryman (2012), sampling is the systematic process of accessing people to participate in a particular research study. Convenience sampling was chosen for this study because this technique minimised the time and costs of conducting the study (Altinay \& Paraskevas, 2008).

Jennings (2010) and Altinay and Paraskevas (2008) state that convenience sampling means that the researchers selected respondents for the study based on 
respondents' convenient accessibility. The sample for the study comprised 300 adult township residents who reside in Soshanguve. Primary data for the study was collected by means of a questionnaire consisting of closed- and open-ended questions.

For the closed questions, a 5-point Likert scale was used. According to Jennings (2010), the main advantage of using primary data is that the findings from the collected data are suitable specifically for the research project at hand. Data analysis for the study was conducted by means of descriptive and inferential statistics, namely factor analysis, Cronbach's alpha and the Wilcoxon signed-rank test.

\section{RESULTS DISCUSSIONS \\ Demographic results}

This section reports on the socio-demographic information of the respondents. Demographic descriptors are inherent, economic, geographical, and social traits that constitute an individual and define the location of that individual in his/her social environment (Reic, 2016, p.90).

\section{Socio-demographic profile of respondents}

This research study obtained 300 usable questionnaires. The gender distribution was $56 \%$ male and $44 \%$ female. This is in contrast to the study conducted by Cheng et al. (2019) on community participation as a mediating factor on residents' attitudes towards sustainable tourism development and their personal environmentally responsible behaviour. In the study of Cheng et al. (2019), the results concerning gender distribution indicated a greater number of females than males. In the current study, the dominant age group was 18-24 years (43\% of respondents), which is in line with the findings of Cheng et al. (2019) that demonstrated the majority of the sample to consist of the youth. In terms of education distribution, the results indicated that most of the respondents were in possession of a national diploma (36\%). Regarding the category for length of time residing in Soshanguve, 35\% of respondents indicated less than five years. In addition, $46 \%$ of the respondents stated that they were living with family. The majority of respondents personally found responsible tourism important (37\%). Lastly, the results demonstrated that $63 \%$ of the respondents had taken a holiday in the past four years, with $50 \%$ indicating that they had taken a responsible holiday in the past four years.

\section{Behavioural descriptors of respondents}

The analysis presented below includes the factor analysis that addresses the grouping of factors.

\section{Factor analysis on behavioural descriptors of township residents}

To address the research aim of identifying behavioural descriptors of township residents regarding responsible tourism practices, an exploratory factor analysis was used to group a large number of variables (Jennings, 2010). Similarly, Bandalos \& Finney (2018) maintain that factor analysis is used to determine the co-variation between a set of detected variables as a function of one or more concealed concepts. To ascertain the adequacy of analysis, this research paper utilised the Kaiser-Meyer-Olkin (KMO) test. The factor analysis showed that the sampling was adequate since the sample size fell within the acceptable criteria and that the original variables could be factorised efficiently. Pallant (2013) specifies that the KMO value should be 0.6 or above.

A principal component factor analysis with varimax rotation of ten Likert-scale questions from the questionnaire used was performed on data gathered from 300 respondents. Factors were retained using the Kaiser criterion in which only factors with Eigen-values of greater than one are retained; hence two factors were retained. The two factors extracted accounted for approximately $61 \%$ of the total variation. The results of an 
orthogonal rotation of the solution are shown in Table 1. Where loadings less than 0.40 were excluded, the analysis yielded a two-factor solution simple structure (factor loadings $=>.40$ ). Five items were loaded on Factor 1; these items incorporated items related to social aspects towards responsible tourism. Factor 1 was named Environmental Care. This factor showed reliability with a Cronbach's alpha coefficient of .860. Table 1 further illustrates the five items loaded on the second factor, which was named Social Responsibility. This factor showed reliability with a Cronbach's alpha coefficient of .797.

Table 1. Factor analysis

\begin{tabular}{|l|c|c|}
\hline \multicolumn{1}{|c|}{ Questionnaire statement } & \multicolumn{2}{c|}{ Factor loading } \\
\cline { 2 - 3 } & 1 & 2 \\
\hline Protection of natural resources & .8415 & \\
\hline Environmental protection & .8473 & \\
\hline Waste reduction & .8217 & \\
\hline Fighting poverty and economic inequality & .5826 & \\
\hline Fairtrade & .6148 & \\
\hline Protecting human rights and protecting against child labour & & .6769 \\
\hline Organic agriculture and food & & .6682 \\
\hline Equal opportunities /fair pay in the workplace & & .8016 \\
\hline Promoting development in the community & & .7141 \\
\hline Animal protection & & .5371 \\
\hline Variance & 3.26766 & 2.85292 \\
\hline Cronbach's a reliability coefficient & .860 & .797 \\
\hline Cumulative \% & .3268 & .6121 \\
\hline
\end{tabular}

\section{Paired comparison results}

The Wilcoxon signed-rank test was used to compare the level of importance of responsible resident behaviour when at home and when travelling. The results are illustrated in Table 2 below. The results of the Wilcoxon signed-rank test indicate that the level of importance regarding the following variables does not differ significantly when travelling and when at home.

Table 1. Factor analysis

\begin{tabular}{|l|l|}
\hline Variable & P-value \\
\hline Separate my waste for recycling & 0.6342 \\
\hline Use environmentally friendly detergents and cleaning products & 0.2274 \\
\hline Take actions to limit my use of electricity & $0.0000^{*}$ \\
\hline Take actions to limit my use of water & $0.0000^{*}$ \\
\hline Use public transport when given the opportunity & 0.7315 \\
\hline Buy organic foods & $0.0307^{*}$ \\
\hline Contribute to organisations devoted to environmental protection & 0.3476 \\
\hline Contribute to organisations devoted to social causes & 0.8065 \\
\hline * indicates that there is a significant difference & \\
\hline
\end{tabular}

- Separating waste for recycling when at home does not differ significantly when travelling, $\mathrm{p}=0.6342$.

- Using environmentally friendly detergents and cleaning products when at home does not differ significantly when travelling, $p=0.2274$. 
- Using public transport when given the opportunity when at home does not differ significantly when travelling, $\mathrm{p}=0.7315$.

- Contributing to organisations devoted to environmental protection when at home does not differ significantly when travelling, $\mathrm{p}=0.3476$.

- Contributing to organisations devoted to social causes when at home does not differ significantly when travelling, $\mathrm{p}=0.8065$.

However, the level of importance allocated to taking actions to limit water usage at home differs significantly when travelling $(\mathrm{Z}=6.457, \mathrm{p}<0.001)$. This action was rated to be more important when at home than when travelling. Taking actions to limit the use of electricity at home differs significantly from taking actions when travelling, which was rated to be more important at home than when travelling. Finally, residents rated the variable, Buy organic foods, to be more important when travelling than when at home, which suggests that when at home, residents pay less attention to what they eat than when they are travelling. The results indicate that when at home, residents are cautious about the amount of water and electricity used. Additionally, the type of food that the residents eat at home versus the type of food eaten when travelling is influenced. These findings could be due to affordability and the avoidance of high electricity bills, given the social standing of a township such as Soshanguve.

\section{CONCLUSION}

Responsible tourism behaviour aims to minimise environmental problems and such behaviour emerges as a solution to the negative environmental impacts created by those who use tourism products and services. Studies suggest that information dissemination through practices such as awareness campaigns may encourage people to be more environmentally responsible when they are at their homes and when they are travelling. Informed people are able to form attitudes and perceptions concerning sustainable development and are more likely to grasp and take preventative measures and offer solutions for environmental issues. Such individuals are capable of showing appreciation and empathy towards environmental and community issues and have a sense of attachment and stewardship. The aim of this study was to segment residents in a South African township by way of examining their attitudes and behaviours towards responsible tourism practices. The results indicated that residents are aware of responsible tourism practices. Protecting human rights and protecting against child labour, ensuring equal rights in the workplace, and waste reduction are some of the behavioural elements that were found. Additionally, the research highlighted that the behaviour and practices of residents when at home and when travelling differed in some of the elements (e.g. the use of water and electricity).

This is because townships in South Africa encounter many social challenges, which as indicated, have a significant effect on residents' behaviour and practices. It is, however, concerning to note that when travelling, residents' use of water and electricity differs from when they are at home. The findings indicated that residents use more water and electricity when travelling than when they are at home. This could be because when travelling, the residents are not liable for the financial implications regarding the amount of water and electricity used. These results may be used to inform tourism policymakers within the City of Tshwane Municipality/Soshanguve of the background of residents' responsible tourism behaviours in addition to how to promote responsible tourism behaviour in townships and how to raise awareness regarding the benefits of responsible tourism behaviour when at home and when travelling. 


\section{Acknowledgements}

As part of an academic project, the authors would like to acknowledge the assistance of the B-Tech students who collected the data at Soshanguve.

\section{REFERENCES}

Alén, E., Losada, N., \& de Carlos, P. (2017). Profiling the segments of senior tourists throughout motivation and travel characteristics. Current Issues in Tourism, 2O(14), 1454-1469.

Altinay, L., \& Paraskevas, A. (2008). Planning research in hospitality and tourism. Abingdon, UK: Routledge.

Anyumba, G. (2017). Planning for a township tourism destination: Considering red flags from experiences in Atteridgeville, South Africa. African Journal of Hospitality, Tourism and Leisure, 6(2), 1-22.

Bandalos, D. L., \& Finney, S. J. (2018). Factor analysis: Exploratory and confirmatory. In G. R. Hancock, R. O. Mueller, \& L. M. Stapleton (Eds.), The reviewer's guide to quantitative methods in the social sciences (pp. 98-122). Abingdon, UK: Routledge.

Barr, S., Shaw, G., Coles, T., \& Prillwitz, J. (2010). A holiday is a holiday: Practicing sustainability, home and away. Journal of Transport Geography, 18(3), 474-481.

Bob, U. (2016). An assessment of responsible tourism behaviour among beach tourists in Durban, South Africa. African Journal of Hospitality, Tourism and Leisure, 5(3), 1-15.

Booyens, I. (2010). Rethinking township tourism: Towards responsible tourism development in South African townships. Development Southern Africa, 27(2), 273-287.

Brida, J. G., Osti, L., \& Barquet, A. (2010). Segmenting resident perceptions towards tourism-a cluster analysis with a multinomial logit model of a mountain community. International Journal of Tourism Research, 12(5), 591-602.

Brida, J., Osti, L., \& Faccioli, M. (2011). Residents' perception and attitudes towards tourism impacts: A case study of the small rural community of Folgaria (Trentino-Italy). Benchmarking: An International Journal, 18(3), 359-385.

Bryman, A. (2012). Social research methods. (4th ed.). New York: Oxford University Press.

Cheng, T. M., Wu, H. C., Wang, J. T. M., \& Wu, M. R. (2019). Community participation as a mediating factor on residents' attitudes towards sustainable tourism development and their personal environmentally responsible behavior. Current Issues in Tourism, 22(14), 1764-1782.

Chili, N. S. (2015). Township Tourism: The politics and socio-economic dynamics of tourism in the South African township: Umlazi, Durban.

Chiu, Y. T. H., Lee, W. I., \& Chen, T. H. (2014). Environmentally responsible behavior in ecotourism: Antecedents and implications. Tourism Management, 4O, 321-329.

Dolnicar, S., Knezevic Cvelbar, L., \& Grün, B. (2019). A sharing-based approach to enticing tourists to behave more environmentally friendly. Journal of Travel Research, 58(2), 241-252.

Dryglas, D., \& Salamaga, M. (2017). Applying destination attribute segmentation to health tourists: A case study of Polish spa resorts. Journal of Travel \& Tourism Marketing, 34(4), 503-514.

Duman, T., \& Tanrisevdi, A. (2011). Profiling of English tourists visiting Turkey based on attitudes toward Internet use in vacation decision making. Journal of Hospitality Marketing \& Management, 2O(5), 525-550.

Eraqi, M. I. (2014). Responsible tourism management as an integrated approach for enhancing the standards of living of local people in Egypt. International Journal of Services and Operations Management, 17(1), 17-37.

George, R., \& Booyens, I. (2014). Township tourism demand: Tourists' perceptions of safety and security. In Urban Forum, 25(4), 449-467. Dordrecht, Netherlands: Springer.

Goyat, S. (2011). The basis of market segmentation: A critical review of literature. European Journal of Business and Management, 3(9), 45-54.

Gross, A. (2010). How slum tourism can change your life: Your life is a trip. Retrieved 3 January 2017 from http://www.yourlifeisatrip.com/home/how-slum-tourism-can-change-your-life.html.

Hanafiah, M. H., Azman, I., Jamaluddin, M. R., \& Aminuddin, N. (2016). Responsible tourism practices and quality of life: Perspective of Langkawi Island communities. Procedia-Social and Behavioral Sciences, 222, 406-413.

Jennings, G. (2010). Tourism research. (2nd ed.). Milton, QLD: John Wiley \& Sons Australia.

Kotler, P., Armstrong, G., Saunders, J., \& Wong, V. (1999). Principles of marketing (2nd European ed.). New Jersey: Prentice Hall.

Liao, Y., \& Satchabut, T. (2017). Factors affecting behavioral intentions and responsible environmental behaviors of Chinese tourists: A case study in Bangkok, Thailand. UTCC International Journal of Business and Economics, 9(2), 137-154.

Mahdzar, M., \& Gani, A. A. (2018). Market segmentation of Kuala Selangor's ecotourists. International Journal of Academic Research in Business and Social Sciences, 8(16), 144-152. 
Maruyama, N., \& Woosnam, K. M. (2015). Residents' ethnic attitudes and support for ethnic neighborhood tourism: The case of a Brazilian town in Japan. Tourism Management, 5O, 225-237.

Nemasetoni, I., \& Rogerson, C. M. (2017). Township tourism in Africa: Emerging tour operators in Gauteng, South Africa. In Urban tourism in the developing world (pp. 205-220). Abingdon, UK: Routledge.

Nkemngu, P. (2012). Community benefit from tourism: Myth or reality a case study of the Soshanguve township. Journal of Tourism \& Hospitality, 1(105), 2167-0269.

Pallant, J. (2013). SPSS survival manual. London: McGraw-Hill Education.

Park, D. B., \& Yoon, Y. S. (2009). Segmentation by motivation in rural tourism: A Korean case study. Tourism Management, $30(1), 99-108$.

Pickard, P. (2007). Is slum tourism in India ethical? Wanderlust, o1 July 2017. Retrieved 30 December, 2018 from <http://www.wanderlust.co.uk/magazine/articles/destinations/indian-slum-tours? page=all.

Poudel, S., \& Nyaupane, G. P. (2017). Understanding environmentally responsible behavior of ecotourists: The reasoned action approach. Tourism Planning \& Development, 14(3), 337-352.

Reic, I. (2016). Events marketing management: A consumer perspective. Taylor \& Francis.

Rid, W., Ezeuduji, I., \& Pröbstl-Haider, U. (2014). Segmentation by motivation for rural tourism activities in the Gambia. Tourism Management, 40, 102-116.

Ridderstaat, J., Croes, R., \& Nijkamp, P. (2014). Tourism and long-run economic growth in Aruba. International Journal of Tourism Research, 16(5), 472-487.

Robert, A. (2010). Epistemology: A contemporary introduction to the theory of knowledge. Abingdon, UK: Routledge.

Rogerson, C. M. (2005). Unpacking tourism SMMEs in South Africa: Structure, support needs and policy response. Development Southern Africa, 22(5), 623-42.

Rosli, T., \& Ahmad, F. S. (2018). A Review on Green Trust and Environmental Quality Awareness Affect Towards Environmental Attitude. In Driving Green Consumerism Through Strategic Sustainability Marketing (pp. 37-49). IGI Global.

Silent, N. D., Ndivhuwo, T., \& Tondani, M. (2018). The Psychographic and Behavioural Descriptors of Ecotourists at Capricorn District Municipality: Segmentation Study. EuroEconomica, 37 (2).

Stylidis, D. (2018). Place attachment, perception of place and residents' support for tourism development. Tourism Planning \& Development, 15(2), 188-210.

Tichaawa, T.M., \& Samhere, S. (2015). Responsible tourism: analysing implementation and challenges in East London using the stakeholder approach. African Journal for Physical Health Education, Recreation and Dance, 21(1/2), 401-414.

Tichaawa, T.M., \& Harilal, V. (2016). Golf tourism in South Africa: profiling attendees at a major championship event management and tourism. African Journal for Physical Activity and Health Sciences, 22(31), 795-807.

Tkaczynski, A., Rundle-Thiele, S. R., \& Beaumont, N. (2009). Segmentation: A tourism stakeholder view. Tourism Management, 3O(2), 169-175./45338/12417872579Introduction_Sustainable_Tourism. pdf/ Introduction_Sustainable_Tourism.pdf

Vanderstoep, S. W., \& Johnston, D. D. (2009). Research methods for everyday life: Blending qualitative and quantitative approaches. CA: John Wiley \& Sons.

Varela-Candamio, L., Novo-Corti, I., \& García-Álvarez, M.T. (2018). The importance of environmental education in the determinants of green behavior: A meta-analysis approach. Journal of Cleaner Production, $170,1565-1578$.

Veisten, K., Haukeland, J. V., Baardsen, S., Degnes-Ødemark, H., \& Grue, B. (2015). Tourist segments for new facilities in national park areas: Profiling tourists in Norway based on psychographics and demographics. Journal of Hospitality Marketing \& Management, 24(5), 486-510.

*** Cape Town Declaration on Responsible Tourism. (2002). Retrieved 19 July 2019 from https://responsibletourismpartnership.org/cape-town-declaration-on-responsible-tourism.

*** National Department of Tourism (NDT). (2017). Retrieved 19 July 2019 from https://www.gov.za/aboutsa/tourism.

*** United Nations Educational, Scientific and Cultural Organization (UNESCO, 2009) Regional Bureau for Science and Culture in Europe (BRESCE). Retrieved 19 July 2019 from http://portal. unesco.org/en/files.

*** World Travel \& Tourism Council (WTTC, 2019). World Economic Impact. Retrieved 23 October 2019 form https://www.wttc.org/-/media/files/reports/economic-impact-research/regions-2019/world2019.pdf.

Submitted:

11.08.2019
Revised:

17.12.2019
Accepted and published online 18.12.2019 